OPEN ACCESS

Edited by:

Jai Prakash,

University of Twente, Netherlands

Reviewed by:

Ricardo Borges,

University of La Laguna, Spain

Jie Li,

Nanjing Medical University, China

${ }^{*}$ Correspondence:

Michele Reni

reni.michele@hsr.it

Angelo Corti

corti.angelo@hsr.it

Specialty section:

This article was submitted to

Cancer Molecular Targets

and Therapeutics,

a section of the journal

Frontiers in Oncology

Received: 02 October 2020 Accepted: 13 November 2020 Published: 23 December 2020

Citation:

Reni $M$, Andreasi V, Gasparri AM, Dugnani E, Colombo B, Macchini M, Bianco M, Dallatomasina A, Citro A, Assi E, Protti MP, Esposito A, Falconi M, Curnis F, Piemonti $L$ and Corti A (2020) Circulating Chromogranin A Is Cleaved Into Vasoregulatory Fragments in Patients With Pancreatic Ductal Adenocarcinoma.

Front. Oncol. 10:613582. doi: 10.3389/fonc.2020.613582

\section{Circulating Chromogranin A Is Cleaved Into Vasoregulatory Fragments in Patients With Pancreatic Ductal Adenocarcinoma}

\author{
Michele Reni ${ }^{1 *}$, Valentina Andreasi ${ }^{2,3,4}$, Anna Maria Gasparri ${ }^{2}$, Erica Dugnani ${ }^{5}$, \\ Barbara Colombo ${ }^{2}$, Marina Macchini ${ }^{1}$, Mimma Bianco ${ }^{2}$, Alice Dallatomasina ${ }^{2}$, \\ Antonio Citro ${ }^{5}$, Emma Assi ${ }^{2}$, Maria Pia Protti ${ }^{6}$, Antonio Esposito ${ }^{7}$, Massimo Falconi ${ }^{3,4}$, \\ Flavio Curnis ${ }^{2}$, Lorenzo Piemonti ${ }^{4,5}$ and Angelo Corti ${ }^{2,4 *}$
}

\begin{abstract}
1 Department of Medical Oncology, IRCCS San Raffaele Scientific Institute, Milan, Italy, ${ }^{2}$ Division of Experimental Oncology, IRCCS San Raffaele Scientific Institute, Milan, Italy, ${ }^{3}$ Pancreatic Surgery Unit, IRCCS San Raffaele Scientific Institute, Milan, Italy, ${ }^{4}$ Faculty of Medicine and Surgery, Vita-Salute San Raffaele University, Milan, Italy, ${ }^{5}$ Diabetes Research Institute, IRCCS San Raffaele Scientific Institute, Milan, Italy, ${ }^{6}$ Division of Immunology, IRCCS San Raffaele Scientific Institute, Milan, Italy,

${ }^{7}$ Experimental Imaging Center, IRCCS San Raffaele Scientific Institute, Milan, Italy
\end{abstract}

Chromogranin A ( $\mathrm{CgA})$, a secretory protein released in the blood by the neuroendocrine system, consists of a mixture of full-length molecules and fragments endowed of vasoregulatory activity. The extent and the role of $\mathrm{CgA}$ fragmentation were investigated in patients with locally advanced or metastatic pancreatic ductal adenocarcinoma (PDAC, $\mathrm{n}=172$ ). Multivariate analysis showed that full-length CgA was associated with better progression free and overall survival, whereas CgA C-terminal fragmentation was associated with worse prognosis. In vitro studies showed that PDAC cells can promote the cleavage of $\mathrm{CgA} \mathrm{C}$-terminal region by activating plasminogen to plasmin. Limited digestion of full-length $\mathrm{CgA}$ with plasmin abolished its anti-angiogenic activity and generated pro-angiogenic molecules. The fragmentation of $\mathrm{CgA}$ C-terminal region was increased also in murine models of PDAC. In these models, the inhibition of CgA fragmentation with aprotinin, an inhibitor of plasmin and other serine proteases, or the blockade of pro-angiogenic fragments with specific antibodies inhibited the growth of PDAC implanted subcutaneously in mice. Finally, administration of full-length CgA to mice bearing orthotopic PDAC reduced tumor perfusion, as measured by contrast-enhanced ultrasound. These findings suggest that PDAC can promote the cleavage of circulating $\mathrm{CgA} \mathrm{C}$-terminal region to generate fragments that regulate the tumor vascular biology and that may represent new potential therapeutic targets.

Keywords: pancreatic ductal adenocarcinoma, chromogranin A, proteolytic processing, plasminogen activators, vasostatin-1

Abbreviations: CgA, chromogranin A; CTS, catestatin; PDAC, pancreatic ductal adenocarcinoma; PPI, proton pump inhibitors; PST, pancreastatin; SERP, serpinin; VS1, vasostatin-1. 


\section{INTRODUCTION}

Pancreatic ductal adenocarcinoma (PDAC), the most common type of pancreatic cancer, is an aggressive malignancy arising from the exocrine epithelial component of the pancreas (1). PDAC currently represents the fourth cause of cancer-related death (2). Despite the increasing incidence, the prognosis of this neoplasm is still poor and the therapeutic options are very limited $(3,4)$. Thus, studies aimed at investigating the mechanisms of PDAC growth and the identification of new prognostic markers and therapeutic targets are of great experimental and clinical relevance.

A growing body of evidence suggests that circulating chromogranin A (CgA), an acidic secretory protein, may represent an important regulating factor of the vascular biology of solid tumors (5-8). This protein is stored in the secretory granules of many normal neuroendocrine cells and neurons $(9,10)$ and is exocytotically released in circulation, reaching 0.2-1 $\mathrm{nM}$ in healthy subjects $(7,11)$. Higher $\mathrm{CgA}$ levels have been detected in patients with neoplastic, cardiovascular, renal, gastrointestinal, and inflammatory diseases, with, in some cases, important diagnostic and prognostic implications $(9,11)$. Structural studies have shown that circulating $\mathrm{CgA}$ consists of a mixture of full-length $\mathrm{CgA}$ $\left(\mathrm{CgA}_{1-439}\right)$ and $\mathrm{CgA}$-derived fragments of different size, including peptides lacking part or the entire $\mathrm{CgA}_{410-439}$ region and shorter fragments (12). $\mathrm{CgA}_{1-439}$ and some of its fragments (e.g., vasostatin-1, catestatin and serpinin) can exert a variety of biological functions in the regulation of cardiovascular system, metabolism and innate immunity (13). Regarding their vascular functions, recent studies have shown that $\mathrm{CgA}_{1-439}$ can exert anti-angiogenic effects at physiological concentrations $(5,6,8)$. An active anti-angiogenic site is located in its C-terminal region, whereas a latent (or less active) site is located in the N-terminal region, this site requiring cleavage of the $\mathrm{Q}_{76}-\mathrm{K}_{77}$ peptide bond to generate $\mathrm{CgA}_{1-76}$ (vasostatin-1), an anti-angiogenic fragment (5). In contrast, cleavage of $\mathrm{R}_{373}-\mathrm{R}_{374}$ site in the $\mathrm{C}$-terminal region generates $\mathrm{CgA}_{1-373}$, a pro-angiogenic fragment $(5,14)$. The proangiogenic activity of $\mathrm{CgA}_{1-373}$ requires the binding of its Pro-Gly-Pro-Leu-Arg 373 site $\left(\mathrm{PGPQLR}_{373}\right)$ to neuropilin-1: accordingly, antibodies against this site (which is cryptic in $\left.\mathrm{CgA}_{1-439}\right)$ can reduce angiogenesis and tumor growth in various animal models of solid tumors (8). Further processing of $\mathrm{CgA}_{1-373}$ to $\mathrm{CgA}_{1-372}$ and consequent loss of the C-terminal arginine, which can occur in the blood, causes loss of neuropilin1 binding and gain of anti-angiogenic activity (8). Thus, cleavage of circulating $\mathrm{CgA}$ in tumors and then in the blood may represent a complex mechanism for the spatio-temporal regulation of the tumor vascular biology. According to this view, a significant correlation between CgA fragmentation at the $\mathrm{R}_{373}-\mathrm{R}_{374}$ site and tumor microvessel density has been observed in the bone marrow of patients with multiple myeloma (12). However, the prognostic value of CgA cleavage on tumor progression and patient survival still remains unexplored. These notions prompted us to investigate the extent of $\mathrm{CgA} \mathrm{N}$ - and C-terminal proteolytic processing in patients diagnosed with PDAC and to explore its prognostic value and function. We show that cleavage of circulating CgA Cterminal region is increased in patients and that CgA cleavage predicts worse progression-free and overall survival. Furthermore, using in vitro and in vivo models of PDAC, we provide data suggesting a role of the plasminogen activator-plasmin system in $\mathrm{CgA}$ cleavage and a function of CgA fragmentation in the regulation of PDAC vascular biology.

\section{MATERIALS AND METHODS}

\section{Patients and Plasma Samples}

Patients with cyto/histologically proven stage III or IV untreated PDAC were enrolled in this study. Additional eligibility criteria included: age 18-70 years and Karnofsky performance status $>60$, or 71-75 years and Karnofsky performance status $>70$ absolute neutrophil count $\geq 1500 / \mathrm{mm}^{3}$, platelet count $\geq 100,000$ / $\mathrm{mm}^{3}$, hemoglobin $\geq 10 \mathrm{~g} / \mathrm{dl}$; serum creatinine $\leq 1.5 \mathrm{mg} / \mathrm{dl}$; total bilirubin $\leq 1.5 \mathrm{mg} / \mathrm{dl}$; transaminases $\leq 3$ times the upper limit of normal. This study was approved by the local ethics committee (OSR-Prot. PACT-19) and was conducted at the San Raffaele Hospital of Milan (authorized organization) following the principles of good clinical trial practice according to the Declaration of Helsinki. A written informed consent was obtained from each patient.

Five milliliters of peripheral blood were collected at baseline, before the beginning of chemotherapy, in a sterile test-tube and centrifuged at 2,500xg for $10 \mathrm{~min}$. Plasma samples were stocked in $0.5 \mathrm{ml}$ aliquots in cryovials and stored at $-80^{\circ} \mathrm{C}$ until measurement.

\section{Recombinant CgA, Fragments, Antibodies, and Immunoassays}

Human $\mathrm{CgA}_{1-439}$ and $\mathrm{CgA}_{1-373}$, were prepared by recombinant DNA technology and characterized by mass spectrometry analysis (sequence), SDS-PAGE, and western blotting analyses as previously reported $(5,6,12,15)$. Polyclonal and monoclonal antibodies against various epitopes of $\mathrm{CgA}$ located in the $\mathrm{N}$-terminal, central and C-terminal regions of $\mathrm{CgA}$ have been prepared as described in Supplementary Materials. Rabbit IgGs against the $\mathrm{CgA}_{368-373}$ epitope (PGPQLR) were purified by affinity chromatography on protein A-sepharose as previously described (8). $\mathrm{CgA}_{1-439}$ and fragments were detected in plasma samples using five sandwich ELISAs based on antibodies against different CgA regions (see Supplementary Methods and Figure S1 for schematic representation of antibody epitopes and assays, and Table S1 for analyte specificity of each assay) $(8,12)$. These assays can selectively detect: a) full-length $\mathrm{CgA}$ (CgA $\left.\left.\mathrm{Cg}_{1-439}-\mathrm{ELISA}\right) ; \mathrm{b}\right)$ full-length $\mathrm{CgA}$ with or without the C-terminal sequence 437-439 $\left(\mathrm{CgA}_{1-436 / 439}-\right.$ ELISA); c) $\mathrm{CgA}_{1-372}$ and $\mathrm{CgA}_{1-373}\left(\mathrm{CgA}_{1-372 / 373}\right.$ -ELISA); d) $\mathrm{CgA}_{1-76}\left(\mathrm{CgA}_{1-76}-\right.$ ELISA); e) full-length $\mathrm{CgA}$ and fragments containing the $\mathrm{N}$-terminal region plus part or the entire central and C-terminal regions, but not $\mathrm{CgA}_{1-76}$ (defined here as "CgA $A_{\text {total }}$ ") (CgA $\mathrm{Atat}_{\text {tol }}$ ELISA) (12).

The cumulative amounts of large fragments lacking the region 410-430 region (e.g., $\mathrm{CgA}_{1-409}, \mathrm{CgA}_{1-394}, \mathrm{CgA}_{1-373}$, plus other potential fragments with unknown $\mathrm{C}$-terminus), were calculated 
as the difference between $\mathrm{CgA}_{\text {total }}$ and $\mathrm{CgA}_{1-436 / 439}$ and collectively called $\mathrm{CgA}_{1-\mathrm{x}}$.

\section{Cells}

Human PDAC cells BxPC-3, Hs766T, MiaPaCa-2, PT45, A8184, murine PDAC cells DT6606, cancer-associated fibroblasts, and human monocytes were obtained and cultured as described in Supplementary Methods.

\section{Endothelial Spheroid Capillary Sprouting Assay}

Endothelial cell spheroid assays were performed using human umbilical vein endothelial cells as described $(6,8)$ (see also Supplementary Methods).

\section{In Vivo Studies in PDAC Animal Models}

All procedures on mice were approved by the San Raffaele Institutional Animal Care and Use Committee, and by the Ministero della Salute of Italy (Author. 596/2016PR and 637). The study was performed at the San Raffaele Hospital (authorized organization) according to institutional guidelines and in compliance with national and international law and policies. Eight-week-old Rag2-/- $\gamma_{c}-/$ - male mice (CIEA and Taconic, Japan) were challenged subcutaneously with $5 \times 10^{6}$ BxPC-3 or HS766T cells, resuspended in $0.9 \%$ sodium chloride and mixed with Cultrex ${ }^{\circledR}$ Basement Membrane Matrix. Blood samples from animals were collected weekly until day 35 and, in the case of HS766T-tumor bearing mice, at day 68. Eight-weekold C57BL/6/N female mice (Charles River Laboratories Italia S.p.A., Calco, Italy) were challenged with subcutaneous injection of $2 \times 10^{6}$ Panc 02 cells in $0.9 \%$ sodium chloride. Tumor growth was monitored weekly by measuring tumor volumes with calipers. The animals were sacrificed when tumor diameter reached $1-1.5 \mathrm{~cm}$.

Syngeneic eight-week-old C57BL/6N male mice (Charles River) were orthotopically injected with DT6606 PDAC cells. To this aim $1 \times 10^{6}$ cells $/ 50 \mu \mathrm{l}$ in phosphate-buffered saline containing 25\% Growth Factor Reduced Matrigel (BD Biosciences) were injected into the pancreas of mice as previously described, with minor modification (16). Mice were treated with $\mathrm{CgA}(1.5 \mu \mathrm{g} /$ mouse, i.p. twice a week, in $0.9 \%$ sodium chloride) or with vehicle alone. Tumor perfusion was monitored by contrast-enhanced ultrasound analysis using a high-performance ultrasonographic scanner designed for small animal imaging (Vevo 2100; Visual Sonics) as described $(6,17)$.

\section{Statistical Methods}

Study endpoints were progression-free and overall survival. Cox proportional hazards models with backward selection were used to estimate independent predictors of progression-free and overall survival. Continuous variables were compared using Mann-Whitney U test or Student's $t$-test, as appropriate. Statistical analysis was performed using the SPSS 25.0 for Mac software (SPSS Inc., Illinois, USA). $P$ values $<0.05$ were considered significant.

\section{RESULTS}

\section{Full-Length $\mathrm{CgA}$ and Various Fragments Are Present in the Peripheral Blood of Healthy Subjects and Patients with PDAC}

Plasma levels of CgA and its fragments were measured in 172 patients with locally advanced or metastatic PDAC (Table S2) and 37 age-matched healthy subjects. To this aim we used five different ELISAs $\left(\mathrm{CgA}_{1-439^{-}}, \mathrm{CgA}_{1-436 / 439^{-}}, \mathrm{CgA}_{1-372 / 373^{-}}, \mathrm{CgA}_{1-76^{-}}\right.$, and $\mathrm{CgA}_{\text {total }}$-ELISA) based on antibodies against different $\mathrm{CgA}$ epitopes. These assays and the analytes detected are described in Table S1 and schematically represented in Figure S1.

The results (Table 1) suggest that in heathy subjects circulating $\mathrm{CgA}$ consists of a mixture of full-length $\mathrm{CgA}_{1-439}$ (median $0.19 \mathrm{nM}$ ) and fragments $\left(\mathrm{CgA}_{\text {total }}, 0.77 \mathrm{nM}\right) . \mathrm{CgA}_{1-436 / 439}$, which include large molecules containing $\mathrm{N}$-terminal, central and part or entire $\mathrm{C}$ terminal region, accounted to about a half of $\mathrm{CgA}_{\text {total }}$, suggesting that a conspicuous amount of the circulating $\mathrm{CgA}$ (about a half) consisted of $\mathrm{CgA}_{1-\mathrm{x}}$, a family of large fragments lacking the entire $\mathrm{C}$-terminal region, some with an undefined $\mathrm{C}$-terminus. Of note, the $\mathrm{CgA}_{1-372 / 373}$ component of the $\mathrm{CgA}$-x family was undetectable in normal subjects (Table 1), suggesting that most $\mathrm{CgA}_{1-\mathrm{x}}$ fragments in healthy subjects were different from $\mathrm{CgA}_{1-372 / 373}$. The results also show that the $\mathrm{N}$-terminal fragment $\mathrm{CgA}_{1-76}$ was present in the blood of healthy subjects, suggesting that partial cleavage of $\mathrm{CgA} \mathrm{N}$ - and C-terminal regions occurs in healthy conditions.

Table 1 also shows the results of assays performed on plasma samples from PDAC patients. Although $\mathrm{CgA}_{\text {total }}$ was not significantly different in healthy subjects and patients, some differences were observed in terms of fragmentation, particularly at the C-terminal region. Indeed, full-length $\mathrm{CgA}_{1-439}$ was significantly decreased in patients, while $\mathrm{CgA}_{1-372 / 373}$ was significantly increased (Table 1 and Figure S2). In contrast, similar levels of $\mathrm{CgA}_{1-76}$ were observed in patients and controls. These data suggest that increased CgA fragmentation at its $\mathrm{C}$-terminal region, but not at its $\mathrm{N}$-terminal regions, occurred in patients. Of note, a modest non-significant increase of $\mathrm{CgA}_{1-\mathrm{x}}$ was observed, suggesting that $\mathrm{CgA}_{1-372 / 373}$ (which belongs to the $\mathrm{CgA}_{1-\mathrm{x}}$ family) mainly derive from another larger $\mathrm{CgA}_{1-\mathrm{x}}$ fragment and in part from full-length $\mathrm{CgA}$. These results, overall, indicate that an important change in the balance between full-length $\mathrm{CgA}$ and fragments, particularly those lacking the $\mathrm{C}$-terminal region, occurred in PDAC patients.

\section{Proton Pump Inhibitor Administration Is Not the Cause of Increased CgA Fragmentation}

Considering that $56 \%$ of the PDAC patients were treated with proton pump inhibitors, a class of drugs that may induce the release of $\mathrm{CgA}$ from enterochromaffin-like cells of the gastric mucosa $(18,19)$, the impact of this treatment on circulating CgA was then assessed. Of note, $\mathrm{CgA}_{1-436 / 439}$ levels were significantly higher in patients treated with proton pump inhibitors, compared to untreated patients ( 0.49 vs $0.42 \mathrm{nM}, P=0.042)$, while $\mathrm{CgA}_{1-372 / 373}$ were similar (Table S3). Furthermore, the $\mathrm{CgA}_{1-\mathrm{x}} / \mathrm{CgA}$ total ratio, which represents a sort of C-terminal 
TABLE 1 | Plasma levels of CgA and fragments in patients with pancreatic ductal adenocarcinoma (PDAC) and in healthy subjects.

\begin{tabular}{|c|c|c|c|}
\hline & Healthy subjects $n=37$ & All patients $n=172$ & $P$ value \\
\hline $\mathrm{CgA}_{\text {total }}(\mathrm{nM})$ & 0.77 & 0.92 & 0.101 \\
\hline Median & $0.62-0.99$ & $0.61-1.58$ & \\
\hline $25^{\text {th }}-75^{\text {th }}$ & $0.39-2.17$ & $0.22-14.28$ & \\
\hline \multicolumn{4}{|l|}{ Min-max } \\
\hline $\mathrm{CgA}_{1-439}(\mathrm{nM})$ & 0.19 & 0.13 & 0.013 \\
\hline Median & $0.11-0.29$ & $0.10-0.17$ & \\
\hline $25^{\text {th }}-75^{\text {th }}$ & $0.03-0.64$ & $0.04-0.99$ & \\
\hline \multicolumn{4}{|l|}{ Min-max } \\
\hline $\mathrm{CgA}_{1-436 / 439}(\mathrm{nM})$ & 0.35 & 0.47 & 0.001 \\
\hline Median & $0.30-0.49$ & $0.32-0.78$ & \\
\hline $25^{\text {th }}-75^{\text {th }}$ & $0.09-0.78$ & $0.05-3.71$ & \\
\hline \multicolumn{4}{|l|}{ Min-max } \\
\hline $\mathrm{CgA}_{1-\mathrm{x}}(\mathrm{nM})$ & 0.41 & 0.44 & 0.775 \\
\hline Median & $0.32-0.62$ & $0.26-0.87$ & \\
\hline $25^{\text {th }}-75^{\text {th }}$ & $0.15-1.39$ & $0.001-11.93$ & \\
\hline \multicolumn{4}{|l|}{ Min-max } \\
\hline $\mathrm{CgA}_{1-372 / 373}(\mathrm{nM})$ & 0.05 & 0.16 & $<0.0001$ \\
\hline Median & $0.05-0.06$ & $0.11-0.26$ & \\
\hline $25^{\text {th }}-75^{\text {th }}$ & $0.03-0.07$ & $0.04-6.73$ & \\
\hline \multicolumn{4}{|l|}{ Min-max } \\
\hline $\mathrm{CgA}_{1-76}(\mathrm{nM})$ & 0.33 & 0.32 & 0.916 \\
\hline Median & $0.28-0.39$ & $0.21-0.45$ & \\
\hline $25^{\text {th }}-75^{\text {th }}$ & $0.11-0.48$ & $0.01-3.61$ & \\
\hline \multicolumn{4}{|l|}{ Min-max } \\
\hline $\mathrm{CgA}_{1-\mathrm{x}} / \mathrm{CgA}_{\text {total }}$ & 0.55 & 0.52 & 0.047 \\
\hline Median & $0.50-0.61$ & $0.42-0.61$ & \\
\hline $25^{\text {th }}-75^{\text {th }}$ & $0.26-0.84$ & $0.001-0.97$ & \\
\hline \multicolumn{4}{|l|}{ Min-max } \\
\hline $\mathrm{CgA}_{1-439} / \mathrm{CgA}_{\text {total }}$ & 0.24 & 0.12 & $<0.0001$ \\
\hline Median & $0.15-0.39$ & $0.09-0.20$ & \\
\hline $25^{\text {th }}-75^{\text {th }}$ & $0.04-0.50$ & $0.01-0.49$ & \\
\hline Min-max & & & \\
\hline
\end{tabular}

Bold text indicate statistically significant values.

fragmentation index, was significantly lower in proton pump inhibitors-treated patients $(0.49$ vs $0.54, P=0.032)$. Thus, proton pump inhibitor administration was not the cause of increased CgA fragmentation observed in these patients.

\section{Enhanced C-Terminal Cleavage of CgA Predicts Progression-Free and Overall Survival in PDAC Patients}

After blood collection, 148 patients (86\%) received a combination of cisplatin, epirubicin, capecitabine and gemcitabine, and 24 patients (14\%) received the same association with docetaxel in place of epirubicin, for 6 months or until disease progression. Follow up data, progression-free and overall survival are shown in Table S4. Patients with locally advanced PDAC had a median progressionfree and overall survival of 10 and 18 months, whereas patients with metastatic disease had a median progression-free and overall survival of 6 and 10 months, respectively. A univariate Coxregression analysis showed that stage of disease, Karnofsky performance status, and baseline CA19.9, but not CgA and its fragments, were significantly associated with progression-free and overall survival (Table S5). However, multivariate analysis showed that CgA and its fragments, in addition to age, stage, Karnofsky Performance Status, baseline CA19.9, and chemotherapy regimen, were all significantly associated with progression-free and overall survival (Table 2). Full-length $\mathrm{CgA}\left(\mathrm{CgA}_{1-439}\right.$, min-max 0.04-0.99
$\mathrm{nM}$ ) was a strong predictor of better outcome, both in terms of progression-free survival (hazard ratio: 0.040, $P<0.0001$ ) and overall survival (hazard ratio: $0.025, P<0.0001$ ). These data indicate that every unit increase of this analyte provides a $96 \%$ risk reduction for progression and a $97.5 \%$ risk reduction for death due to any cause. In contrast, a high $\mathrm{CgA}_{1-\mathrm{x}} / \mathrm{CgA}_{\text {total }}$ ratio, an index of $\mathrm{CgA}$ fragmentation in the C-terminal region, was a strong predictor of poor overall survival (hazard ratio: 3.533, $P=0.015$ ), with every unit of this index providing a $253 \%$ risk increase for death due to any cause. An association with a worse prognosis was found also for $\mathrm{CgA}_{1-372 / 373}$ (progression-free survival, hazard ratio: 1.522, $P=0.020$ ) and for $\mathrm{CgA}_{1-436 / 439}$ (overall survival, hazard ratio: 1.595, $P=0.006)$. No association was observed with $\mathrm{CgA}_{1-76}$ or $\mathrm{CgA}_{1-76} /$ $\mathrm{CgA}_{\text {total }}$ ratio. In conclusion, the results of the immunoassays suggest that enhanced fragmentation of circulating $\operatorname{CgA}$ and consequent decrease of full-length $\mathrm{CgA}$ and increase of fragments lacking the C-terminal region is associated with worse outcome in PDAC patients.

\section{Pancreatic Cancer Cell Lines Promote CgA C-Terminal Cleavage By Activating Plasminogen to Plasmin}

The mechanism of CgA fragmentation was then investigated. To investigate the role of cancer cells on $\mathrm{CgA}$ fragmentation we incubated recombinant $\mathrm{CgA}_{1-439}$ in the presence or absence of 
TABLE 2 | Multivariate Cox-regression analysis evaluating predictors of progression-free survival and overall survival (OS) in patients with locally advanced or metastatic pancreatic ductal adenocarcinoma (PDAC) $(n=172)$.

\begin{tabular}{|c|c|c|c|c|c|c|}
\hline \multirow[t]{2}{*}{ Variable } & \multicolumn{3}{|c|}{ Progression-free survival } & \multicolumn{3}{|c|}{ Overall survival } \\
\hline & $H_{R}{ }^{a}$ & 95\% C.I. & $P$ & $\mathrm{HR}^{\mathrm{a}}$ & 95\% C.I. & $P$ \\
\hline Sex & - & - & - & 1 & - & 0.093 \\
\hline Female & & & & 1.312 & $0.956-1.801$ & \\
\hline Male & & & & & & \\
\hline \multicolumn{7}{|l|}{ Age } \\
\hline$\leq 60$ years & 1 & - & 0.002 & 1 & - & 0.020 \\
\hline$>60$ years & 0.602 & $0.437-0.830$ & & 0.685 & $0.497-0.943$ & \\
\hline \multicolumn{7}{|l|}{ Stage } \\
\hline III & 1 & - & $<0.0001$ & 1 & - & $<0.0001$ \\
\hline IV & 2.821 & 1.994-3.992 & & 2.140 & $1.534-2.985$ & \\
\hline Karnofsky performance status & 0.960 & $0.940-0.980$ & $<0.0001$ & 0.965 & $0.945-0.985$ & 0.001 \\
\hline CA 19.9 & 1.017 & $1.005-1.030$ & 0.007 & 1.022 & $1.009-1.034$ & $<0.0001$ \\
\hline \multicolumn{7}{|l|}{ Chemotherapy regimen } \\
\hline PDXG & 1 & - & 0.006 & 1 & - & 0.078 \\
\hline PEXG & 1.978 & $1.219-3.209$ & & 1.550 & $0.952-2.523$ & \\
\hline Proton pump inhibitors & - & - & - & - & - & - \\
\hline \multicolumn{7}{|l|}{ No } \\
\hline \multicolumn{7}{|l|}{ Yes } \\
\hline $\mathrm{CgA}_{\text {total }}$ & - & - & - & - & - & - \\
\hline $\mathrm{CgA}_{1-439}$ & 0.040 & $0.007-0.239$ & $<0.0001$ & 0.025 & $0.003-0.174$ & $<0.0001$ \\
\hline $\mathrm{CgA}_{1-436 / 439}$ & 1.400 & $0.960-2.041$ & 0.080 & 1.595 & $1.143-2.225$ & 0.006 \\
\hline $\mathrm{CgA}_{1-\mathrm{x}}$ & - & - & - & - & - & - \\
\hline $\mathrm{CgA}_{1-372 / 373}$ & 1.522 & $1.069-2.167$ & 0.020 & - & - & - \\
\hline $\mathrm{CgA}_{1-76}$ & - & - & - & - & - & - \\
\hline $\mathrm{CgA}_{1-\mathrm{x}} / \mathrm{Cg} \mathrm{A}_{\text {total }}$ & 2.384 & $0.891-6.380$ & 0.084 & 3.533 & $1.276-9.782$ & 0.015 \\
\hline $\mathrm{CgA}_{1-439} / \mathrm{CgA}_{\text {total }}$ & - & - & - & - & - & - \\
\hline
\end{tabular}

HR, hazard ratio; C.I., confidence interval; PDXG, cisplatin+docetaxel+capecitabine+gemcitabine; $P$ EXG, cisplatin+epirubicin+capecitabine+gemcitabine.

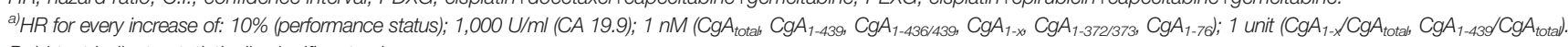

Bold text indicate statistically significant values.

various human PDAC cell lines (Hs766T, MiaPaCa-2, BxPC-3, A8184, PT45, and PaCa44 cells) or murine Panc02 cells. CgA fragmentation in cell supernatants was monitored using $\mathrm{CgA}_{1-439^{-}}$ and $\mathrm{CgA}_{\text {total }}$-ELISA. After 30 min of incubation, little or no changes in $\mathrm{CgA}_{1-439} / \mathrm{CgA}_{\text {total }}$ ratio were observed with all cell lines tested, arguing against a direct role of PDAC cells in CgA fragmentation. However, when plasminogen was added to the cultures, a marked reduction of $\mathrm{CgA}_{1-439} / \mathrm{CgA}_{\text {total }}$ ratio was observed with the majority of PDAC cell lines (Figure 1). The addition of plasminogen activator inhibitor 1 (PAI-1) or of aprotinin (an inhibitor of plasmin and other serine proteases) significantly inhibited the degradation of $\mathrm{CgA}$ by most PDAC cell lines, pointing to a crucial role of plasminogen activators and plasmin in this process (Figure 1). These data suggest that PDAC cells can promote CgA cleavage by releasing plasminogen activators and, consequently, by converting plasminogen into active plasmin. Similar experiments were performed with human cancer-associated fibroblasts isolated from two PDAC (CAF-1 and CAF-2) or with human monocytederived macrophages. No significant degradation was observed with cancer-associated fibroblasts after $30 \mathrm{~min}$, even in the presence of plasminogen (Figure 1). However, partial degradation was observed after $3 \mathrm{~h}$ of incubation, suggesting that also these cells may contribute to CgA degradation, although less efficiently than cancer cells. The same applies also for human monocyte-derived macrophages (Figure 1). Considering that both cell types may represent a large component of the tumor tissues, their contribution to CgA degradation could also be relevant.

\section{The C-Terminal Region of CgA Is More Prone to Plasmin Cleavage Than the N-Terminal Region}

To gain more information on the sites cleaved by plasmin, fulllength CgA was incubated with a small amount of this enzyme for various time intervals. The products were then analysed by SDS-PAGE and mass spectrometry. After $6 \mathrm{~h}$ of incubation, SDSPAGE showed major bands corresponding to undigested CgA (70 $\mathrm{kDa}$ ), large fragments of about $60-65 \mathrm{kDa}$, and $\sim 10 \mathrm{kDa}$ small fragments (Figure 2A, left). The large $60-65 \mathrm{kDa}$ fragments, but not the $\sim 10 \mathrm{kDa}$ fragments, were recognized by an antiserum against the central region of $\mathrm{CgA}(\alpha \mathrm{FRs})$, by western blot analysis (Figure $\mathbf{2 A}$, right), pointing to $\mathrm{N}$ - or $\mathrm{C}$-terminal cleavage. The large fragments were not detectable by mass spectrometry for unknown reasons. However, this assay could identify a series of other subfragments, present in smaller amounts, which were consistent with limited digestion at various sites in the $\mathrm{C}$-terminal region (residues 246-439), but not in the N-terminal region (1-245) of CgA (Figure 2B). Notably, fragmentation of the N-terminal part required longer time to occur $(96 \mathrm{~h}$ ), which implies that the $\mathrm{N}$-terminal part is more resistant than the $\mathrm{C}$-terminal part to plasmin digestion. Taking into consideration the molecular weight of the major fragments (60-65 $\mathrm{kDa}$, determined by SDS-PAGE) and the cleavage sites identified by mass spectrometry after $6 \mathrm{~h}$, we estimate that the large fragments observed by SDS-PAGE and western blotting correspond to CgA cleavage in the C-terminal region, presumably at residues 394, 373, and/or 355/359. Indeed, cleavage at these sites is expected to shorten 

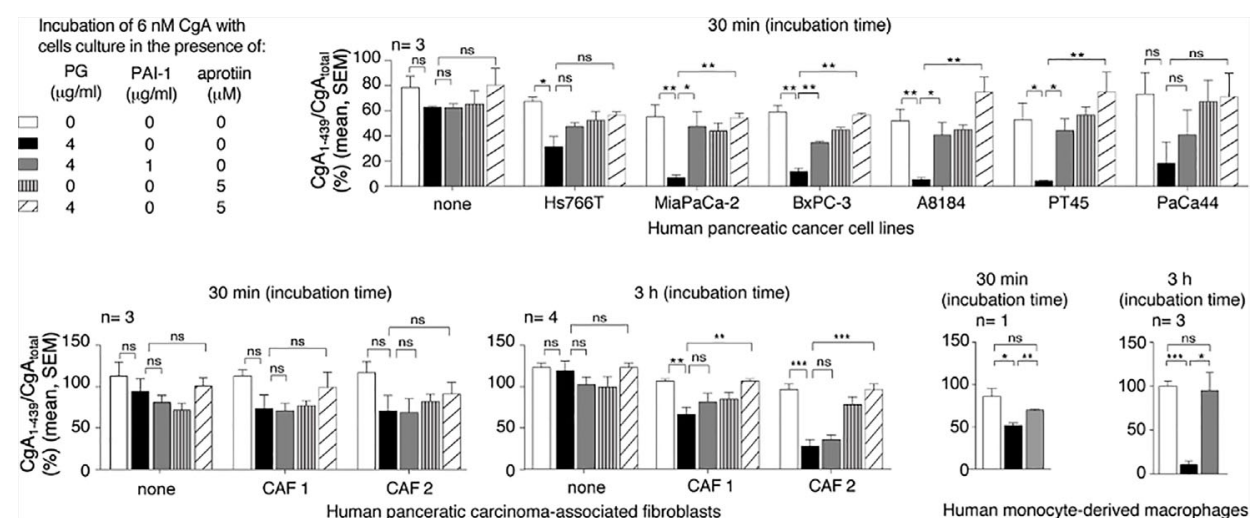

FIGURE 1 | Effect of pancreatic ductal adenocarcinoma (PDAC) cells, pancreatic adenocarcinoma-associated fibroblasts and human monocyte-derived macrophages on CgA cleavage. Human PDAC cells (Hs766T, MiaPaCa-2, BxPC-3, A8184, PT45, PaCa44), PDAC-associated fibroblasts (CAF1 and CAF2) and monocyte-derived macrophages $\left(5 \times 10^{5} \mathrm{cells} /\right.$ well of 96 -well plates) were cultured for $24-48 \mathrm{~h}$ at $37^{\circ} \mathrm{C}$. After washing, recombinant $\mathrm{CgA}{ }_{1-439}(6 \mathrm{nM})$, plasminogen (PG) $(4 \mu \mathrm{g} / \mathrm{ml})$, plasminogen activator inhibitor-1 (PAl-1) $(1 \mu \mathrm{g} / \mathrm{ml})$ and aprotinin $(5 \mu \mathrm{M})$ were added to cell culture medium containing $0.5 \%$ of bovine serum albumin,

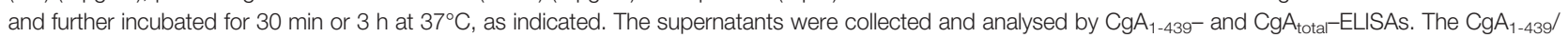
$\mathrm{CgA}_{\text {total }}$ ratio, which represent an index of $\mathrm{CgA}$ integrity, is shown. Bars (mean $\pm \mathrm{SEM}$ ); $P<0.05$; ${ }^{\star \star} P<0.01$; ${ }^{* \star \star} P<0.001$ (t-test, two tails); $n s$, not significant.

the molecule of $45-84$ residues $(\sim 5-10 \mathrm{kDa})$, as observed by SDSPAGE. In conclusion, these results suggest that limited digestion with plasmin can generate large fragments ending with residues 394,373 , and/or 355/359, which are all components of the $\mathrm{CgA}_{1-\mathrm{x}}$ family. This view is in keeping with previous observation showing that an antibody specific for the PGPQLR epitope of $\mathrm{CgA}_{1-373}$ (cryptic in intact $\mathrm{CgA}$ ) could recognize a $60-62 \mathrm{kDa}$ band by western blotting analysis of $\mathrm{CgA}$ digested with plasmin for 2-6 h (12), likely corresponding to the $\mathrm{CgA}_{1-373}$ analyte detected in plasma samples of PDAC patients (Figure S2).

\section{Limited Digestion With Plasmin Converts Anti-Angiogenic Full-Length CgA Into Pro-Angiogenic Fragments}

We have previously shown that $\mathrm{CgA}_{1-439}$ and $\mathrm{CgA}_{1-373}$ are anti- and pro-angiogenic molecules, respectively (5). To assess the impact of plasmin digestion on the biological activity of $\mathrm{CgA}_{1-439}$, we analysed its anti-/pro-angiogenic activity before and after exposure to plasmin, using the endothelial cell spheroid capillary sprouting assay. As expected, limited digestion of $\mathrm{CgA}_{1-439}$ caused loss of anti-angiogenic activity and gain of pro-angiogenic effects, as indicated by the lower number of capillary-like sprouts induced by CgA before digestion and by the higher number of sprouts after $2-16$ h of incubation, compared to untreated spheroids (Figure 2C). Extensive digestion for $24 \mathrm{~h}$ reduced the pro-angiogenic effects. These results suggest that limited digestion of CgA C-terminal region by plasmin is associated with a marked change of function, from anti- to pro-angiogenic.

\section{CgA C-Terminal Fragmentation Is Increased in Mouse Models of PDAC}

To assess whether PDAC cells can cause CgA fragmentation also in vivo, we monitored CgA levels in plasma samples obtained from C57BL/6 mice bearing subcutaneous Panc02 tumors (Figure 3A), using $\mathrm{CgA}_{1-439^{-}}$and $\mathrm{CgA}_{\text {total }}$-ELISA (taking advantage from antibody cross-reactivity with the murine fulllength $\mathrm{CgA}_{1-445}$ and $\left.\mathrm{CgA}_{\text {total }}\right)$. A significant decrease of fulllength $\mathrm{CgA} / \mathrm{CgA}$ total ratio was observed from day 3 to day 31-48 after tumor implantation (Figure 3B, left). This finding is consistent with an increased proteolytic processing of circulating CgA upon tumor growth. Of note, the full-length $\mathrm{CgA} / \mathrm{CgA}_{\text {total }}$ ratio negatively correlated with tumor volume (Figure 3B, right), likely because large amounts of protease are produced by large tumors. Similar results were observed also in other models based on human BxPC-3 or Hs766T PDAC cells implanted subcutaneously in $\mathrm{Rag}^{-/-} \mathrm{\gamma c}^{-/-}$mice (Figures 4A-C). Interestingly, in the BxPC-3 model the tumor burden positively correlated with $\mathrm{CgA}_{1-\mathrm{x}} / \mathrm{CgA}_{\text {total }}$ ratio (Figure 4B, right), pointing again to enhanced C-terminal fragmentation by larger tumors. These findings suggest that also in these models tumor growth was associated with an increased CgA fragmentation, particularly in the C-terminal region, as observed in patients.

\section{The Growth of Subcutaneous Panc02 Tumors Is Inhibited By Administration of Aprotinin or Anti-PGPQLR Antibodies}

To assess the hypothesis that $\mathrm{CgA}$ fragmentation has a role in the regulation of tumor progression, mice bearing subcutaneous Panc02 tumors were treated with aprotinin (to inhibit CgA fragmentation). A significant reduction of the full-length $\mathrm{CgA} /$ $\mathrm{CgA}_{\text {total }}$ ratio was observed from day 24 to 39 in mice treated with the diluent, pointing to $\mathrm{CgA}$ cleavage, but not in mice treated with aprotinin (Figure 5A, left). These data suggest a role of a serine protease, possibly plasmin, in CgA cleavage. Notably, aprotinin could also reduce the tumor growth rate (Figure 5A, right), suggesting that $\mathrm{CgA}$ fragmentation contributed to tumor growth regulation.

To assess this hypothesis, Panc02-bearing mice were injected with anti-PGPQLR IgGs, previously shown to a) neutralize the neuropilin-1 binding site of human $\mathrm{CgA}_{1-373}\left(\mathrm{PGPQLR}_{373}\right)$, 
A

Time of incubation with plasmin-sepharose (h)

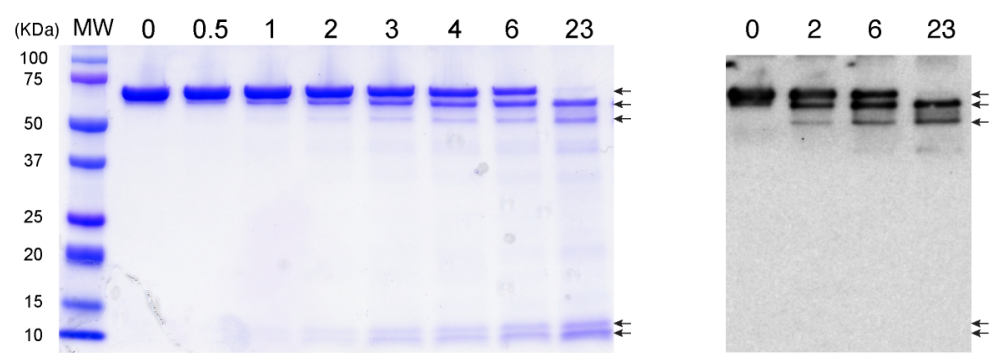

B

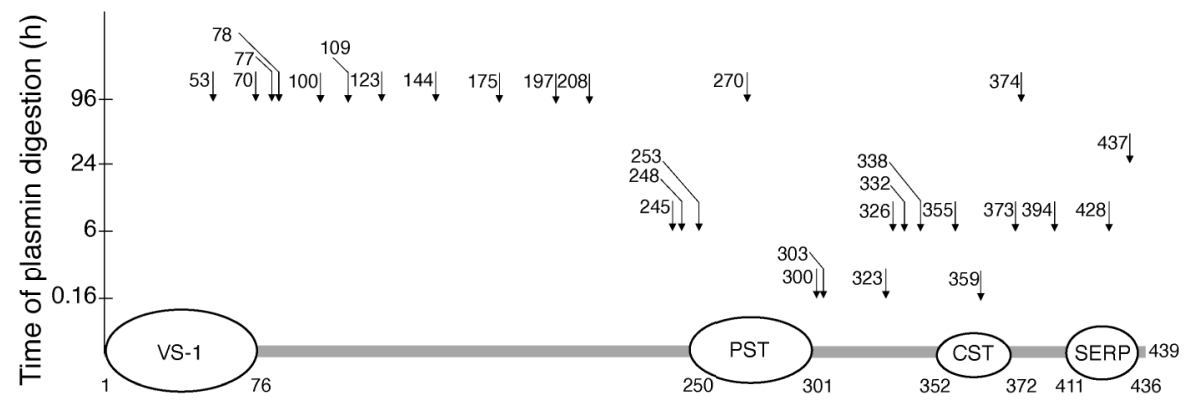

C

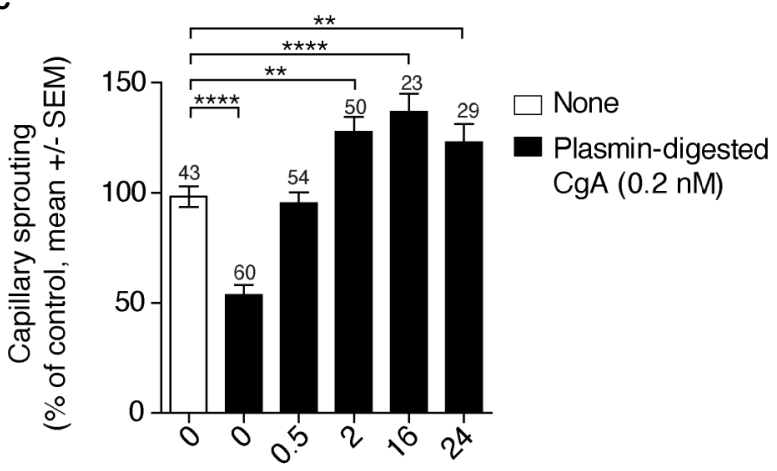

Time of plasmin digestion (h)

FIGURE 2 | Time course of CgA cleavage by plasmin, cleavage sites, and anti-/pro-angiogenic activity before and after cleavage. (A) SDS-PAGE and western blotting analysis of $\mathrm{CgA}$ before and after digestion with plasmin. Recombinant full-length $\mathrm{CgA}_{1-439}(9 \mu \mathrm{M}, 100 \mu \mathrm{l})$ was incubated with plasmin-Sepharose beads (BioVision) (10 $\mathrm{\mu l}$ ) in $0.05 \mathrm{M}$ sodium chloride, $0.15 \mathrm{M}$ sodium phosphate buffer, $\mathrm{pH}$ 7.3, for the indicated time. At various time points, the beads were removed, by centrifugation, and the supernatants were analysed by SDS-PAGE (Coomassie dye staining) (left panel) and western blotting with the $\alpha$ FRs antiserum against the central region of CgA (right panel). MW, molecular markers. (B) Schematic representation of full-length $\mathrm{CgA}$ and its plasmin cleavage sites (arrows and number of cleaved residue) identified by mass spectrometry analysis of the low molecular weight fragments obtained by limited and extensive digestion of CgA with plasminsepharose. The time of digestion is indicated on the y axis. As shown the $\mathrm{C}$-terminal region is more prone to proteolysis than the $\mathrm{N}$-terminal region, the latter requiring $96 \mathrm{~h}$ of incubation for cleavage. The regions corresponding to vasostatin-1 (VS-1); pancreastatin (PST); catestatin (CST); and serpinin (SERP) are indicated. (C) Effect of plasmin cleavage on the anti-angiogenic activity of full-length $\mathrm{CgA}$, as measured using the endothelial-spheroid capillary-sprouting assay. In a separate digestion experiment, plasmin-Sepharose was removed by centrifugation at the indicated time points; the supernatants, diluted to $0.2 \mathrm{nM} \mathrm{CgA}$, were incubated overnight with endothelial cell spheroids. Each bar represents the number of capillaries sprouting from the spheroids (mean \pm SEM, see Methods). The number of spheroids analysed for each time point is indicated on each bar. ${ }^{\star \star} P<0.01$; ${ }^{\star \star \star \star} P<0.0001$ (t-test, two tails).

b) cross-react with the corresponding site of its murine counterpart (100\% conserved), and c) inhibit tumor growth in various murine models of solid tumors (8). Systemic administration of these antibodies, but not of normal rabbit
IgGs, significantly reduced tumor growth (Figure 5B). As these antibodies cannot cross-react with the cryptic PGPQLR site of full-length $\operatorname{CgA}$ (8), these data support the hypothesis that $\operatorname{CgA}$ cleavage at this site contributed to tumor growth. 

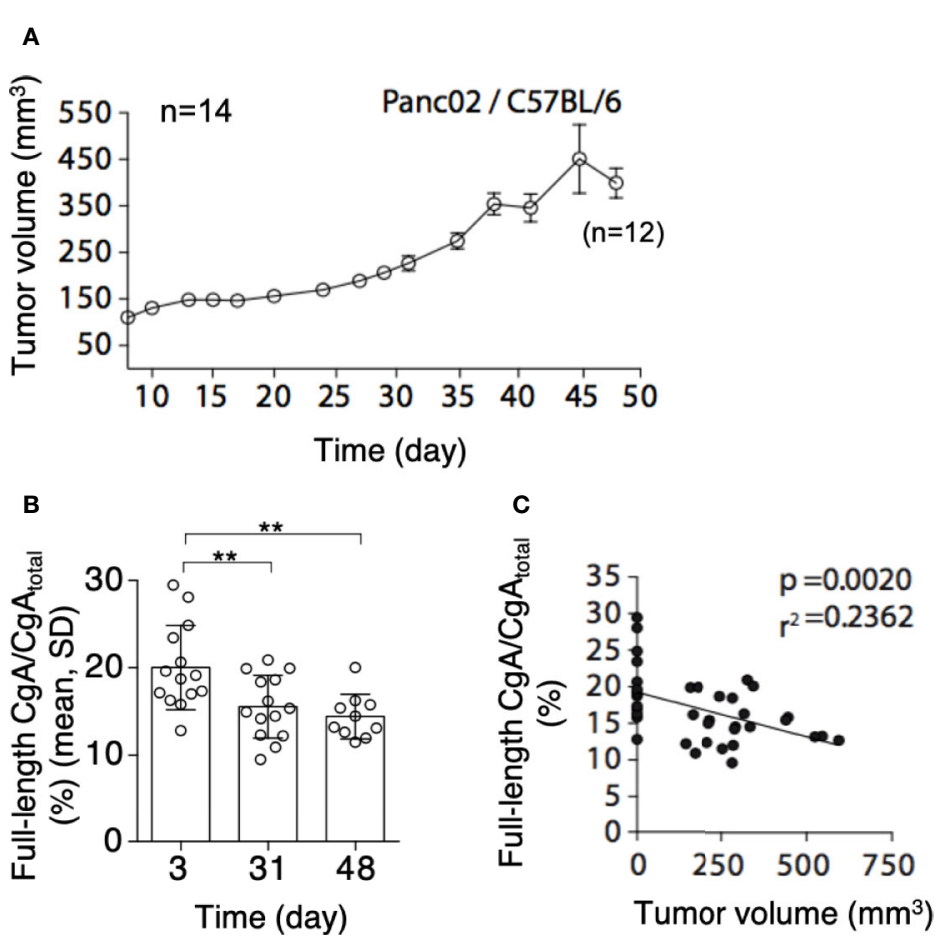

FIGURE 3 | Tumor growth and CgA fragmentation in the murine Panc02 model. (A) Growth rate of Panc02 tumors implanted subcutaneously in syngeneic mice. Tumor volumes were measured with calipers (mean \pm SEM, n=14). As 2 mice died at day 48, the data reported at this time point represent the tumor volumes of 12 mice. (B) Endogenous full-length $\mathrm{CgA}_{\mathrm{CgA}}$ total ratio (an index of $\mathrm{CgA}$ integrity) as measured at day 3, 31 and 48 after tumor implantation. Endogenous full-length $\mathrm{CgA}$ and $\mathrm{CgA}_{\text {total }}$ were measured by ELISA of plasma samples collected at day 3 and 31 ( $\mathrm{n}=14$ ). Only 10 plasma samples (from 12 surviving mice) were collected in

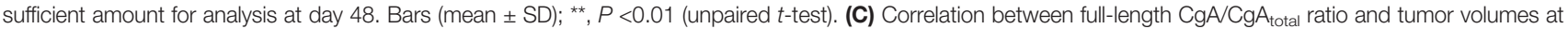
day 3,31 , and 48 . The tumor volumes at day 3 , undetectable, were considered $<1 \mathrm{~mm}^{3}$.

\section{Recombinant CgA Can Affect Tumor Perfusion in an Orthotopic Model}

Finally, we investigated the effect of exogenous CgA on tumor vasculature and perfusion using DT6606 PDAC cells implanted orthotopically in the pancreas of syngeneic mice. To this aim, tumor-bearing mice were treated twice a week with $1.5 \mu \mathrm{g}$ of fulllength CgA (i.p.). Tumor perfusion was monitored one day before treatment (day 13) and three days after the last treatment (day 41), by contrast-enhanced ultrasound analysis with microbubbles. A significant decrease of the final/basal ratio of the wash-in area under the curve (WiAUC) and rise time (RT) of microbubbles was noted in animals treated with CgA (Figure 6). These data suggest that full-length CgA could affect the tumor vascular physiology and reduce perfusion of tumor tissues in this PDAC model.

\section{DISCUSSION}

The results show that fragmentation of the circulating pool of $\mathrm{CgA}$ is associated with shorter progression-free and overall survival in patients with PDAC. In particular, a decrease of full-length CgA and a relative increase of fragments lacking all or part of the C-terminal region $\left(\mathrm{CgA}_{1-\mathrm{x}}\right)$ were found in plasma samples of patients with worse prognosis (Table 2). Although the N-terminal fragment $\mathrm{CgA}_{1-76}$ was also detected in these patients, only the $\mathrm{CgA}_{1-\mathrm{x}} /$ $\mathrm{CgA}_{\text {total }}$ ratio, and not the $\mathrm{CgA}_{1-76} / \mathrm{CgA}_{\text {total }}$ (i.e., C- and $\mathrm{N}$ terminal fragmentation indexes, respectively), was associated with patient prognosis. It appears, therefore, that fragmentation of the CgA C-terminal region is more relevant than fragmentation of the $\mathrm{N}$-terminal region for patient prognosis.

Considering that administration of proton pump inhibitors is known to induce enterochromaffin-like cell hyperplasia and CgA secretion from the gastric mucosa $(18,19)$, the question arises as to whether these drugs induced the change in the circulating pool of full-length CgA and fragments observed in PDAC patients. This hypothesis is ruled out by the observation that patients taking proton pump inhibitors had a lower C-terminal fragmentation index, compared to untreated patients (Table S3). These and the above findings raise the question as to whether enhanced $\mathrm{CgA}$ cleavage in PDAC patients, e.g., at residue $R_{373}$, occurred in neuroendocrine secretory cells (by intragranular or extracellular proteases), in the blood, or in tumors, by locally produced proteases. The results of a series of in vitro and in vivo studies performed with $\mathrm{PDAC}$ experimental models suggest that CgA fragments were produced in tumor tissues, by tumor-derived proteases. In particular, in vitro studies performed with various cultured human PDAC cell lines showed that these cells can promote the cleavage of exogenous full-length 

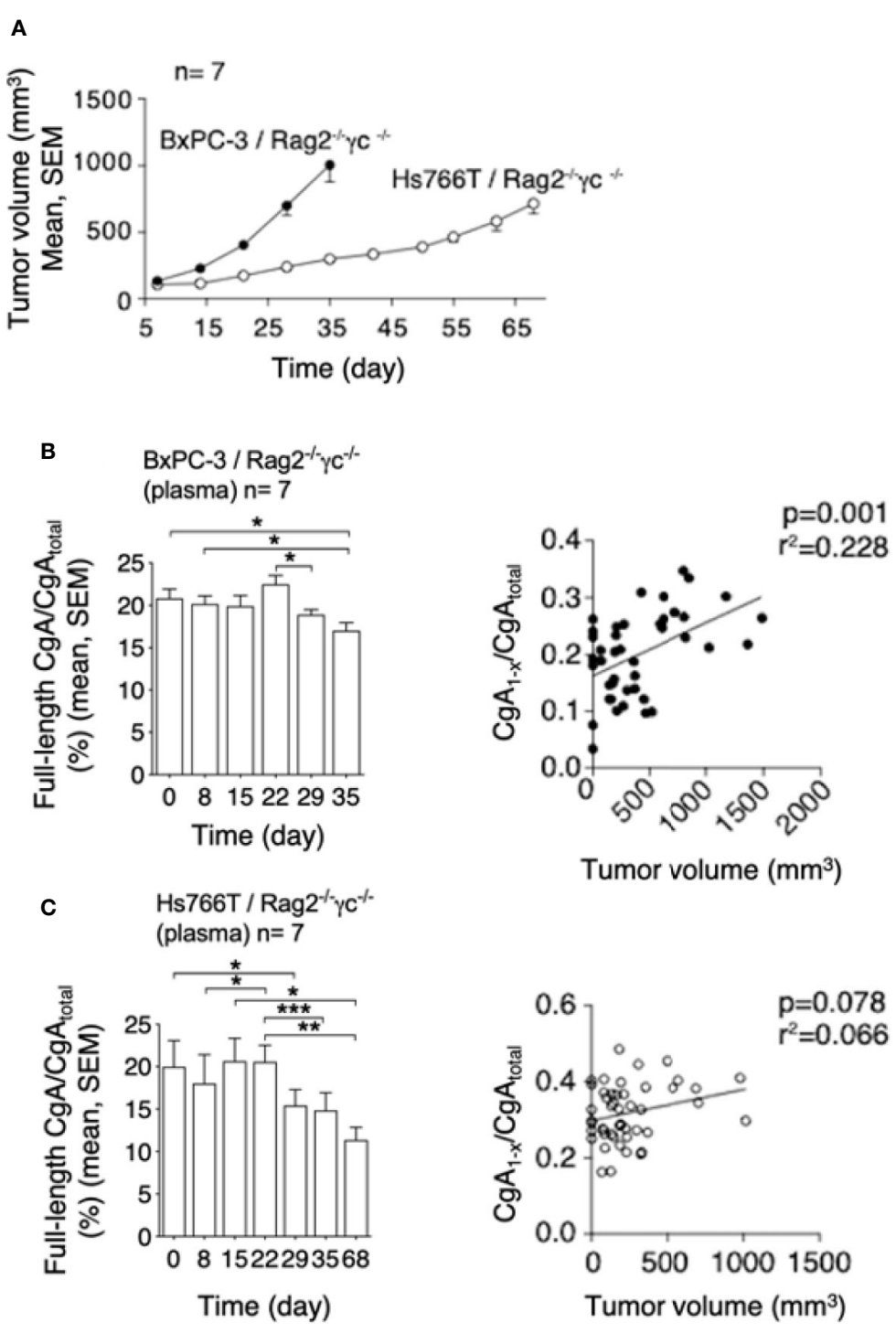

FIGURE 4 | Tumor growth and CgA fragmentation in the human BxPC-3 and Hs766T models. (A) Growth rate of BxPC-3 and Hs766T tumors implanted subcutaneously in Rag2 ${ }^{-1-} \mathrm{\gamma c}^{-/-}$mice $(\mathrm{n}=7)$. Tumor growth was monitored with calipers. (B, C) Left pane/s: endogenous full-length CgA/CgA integrity) at the indicated time points after tumor implantation. Circulating full-length CgA and CgA total were measured by ELISA of plasma samples collected at the indicated time. Bars (mean $\pm \mathrm{SEM}$ ); ${ }^{\star} P<0.05$; ${ }^{\star \star} P<0.01$; ${ }^{\star \star \star} P<0.001$ (paired $t$-test). Right panels: correlation between $\mathrm{CgA}_{1-\mathrm{x}} / \mathrm{CgA} \mathrm{A}_{\text {total }}$ ratio (an index of CgA Cterminal degradation) and tumor volume, as measured in various mice at various times.

CgA added to the cell cultures (Figure 1). Interestingly, no cleavage was observed when plasminogen was omitted or when plasminogen activator inhibitor- 1 was added to the cell cultures, pointing to an important role of plasminogen activators and plasmin in CgA cleavage. Accordingly, also aprotinin, an inhibitor of plasmin and other serine proteases, could inhibit CgA cleavage by these cells. CgA cleavage was observed also with cultured human monocyte-derived macrophages or with cancerassociated fibroblasts derived from PDAC. Although macrophages and cancer-associated fibroblasts required much longer time than cancer cells to induce CgA cleavage, also these cells might significantly contribute to $\mathrm{CgA}$ cleavage in patients, given their considerable abundance in the tumor stroma. Thus, various kinds of cells potentially present in the tumor tissue may contribute, to a different extent, to CgA cleavage.

This view is further supported by the results of in vivo studies, showing that the growth of murine Panc02, human BxPC3, or human Hs766T PDAC cells implanted subcutaneously in mice is associated with increased fragmentation of circulating CgA (Figures 3 and 4). Notably, a significant correlation between tumor volume and $\mathrm{CgA}$ cleavage was observed in the Panc02 and BxPC3 models, possibly because large tumors could release more proteolytic enzymes. Furthermore, in the Panc02 model, aprotinin could significantly inhibit CgA fragmentation (Figure 5), pointing again to a role of a serine protease in CgA cleavage. 
A
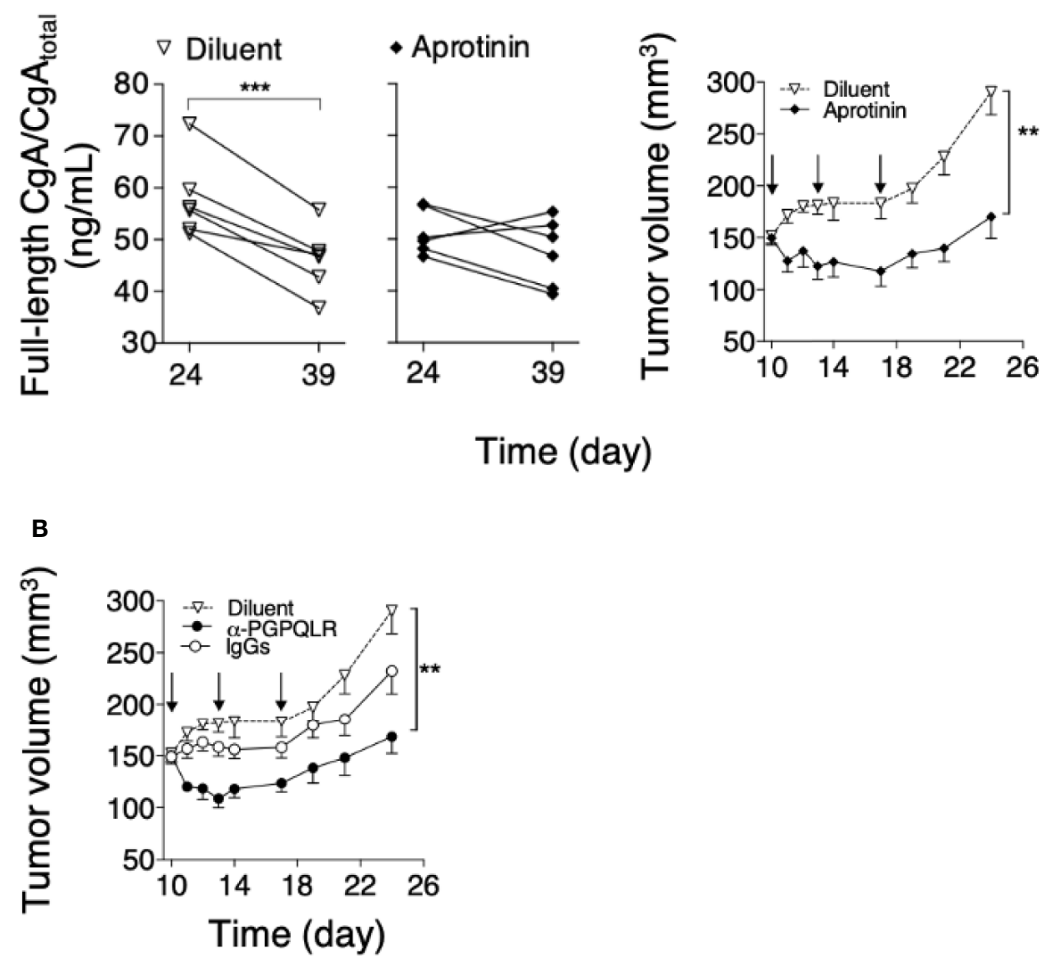

FIGURE 5 | Effect of aprotinin or anti-PGPQLR antibodies on Panc0-tumor growth in mice. (A) Effect of aprotinin on the degradation of circulating CgA (left) and on the growth of Panc02-tumors (right). Panc02 tumor-bearing mice ( $n=6 / g r o u p)$ were treated at day 10, 13 and 17 (arrows) with intra-peritoneal injections of aprotinin (100 $\mu \mathrm{g} /$ mouse) or diluent (saline solution). Plasma samples were collected from each mouse at day 24 and 39 and analyzed by full-length CgA-ELISA and CgAtotal ELISA. The full-length $\mathrm{CgA} / \mathrm{CgA}_{\text {total }}$ ratio (an index of C-terminal integrity) was then calculated (left pane/s); ${ }^{\star \star \star} P<0.001$ (paired $t$-test). Tumor volumes (right panel) were measured with calipers (mean $\pm \mathrm{SEM}$ ); ${ }^{\star \star} P<0.01$ (unpaired $t$-test). (B) Effect of anti-PGPQLR (Pro-Gly-Pro-Gln-Leu-Arg) antibodies (capable of neutralizing the neuropilin-1 binding site of $\mathrm{CgA}_{1-373}$ ) on Panc02-tumor growth. Tumor-bearing mice were treated (i.p) at the indicated time (arrows) with $50 \mu \mathrm{g} / \mathrm{mouse}$ of rabbit antiPGPQLR IgGs or control lgGs, or saline solution (Diluent). Tumor volumes (mean $\pm \mathrm{SEM}$ ); ${ }^{\star \star} P<0.01$ (two tailed $t$-test).

The capability of plasmin to preferentially cleave the Cterminal region of CgA is supported by the results of SDSPAGE, western blotting, and mass spectrometry analysis of CgA fragments obtained after limited or extensive digestion of recombinant $\mathrm{CgA}$ with plasmin (Figure 2). Indeed, analysis of the time course of $\mathrm{CgA}$ degradation with these techniques showed that certain sites located in the C-terminal region, e.g., at residue $355,359,373$, and/or 394 , are more prone to plasmin cleavage than sites located in the $\mathrm{N}$-terminal region, the latter sites requiring a markedly longer time of incubation for cleavage. Thus, the results of in vitro and in vivo studies suggest that PDAC can promote the cleavage of CgA C-terminal region by activating plasminogen to plasmin, which in turn preferentially cleaves $\mathrm{CgA}$ in the $\mathrm{C}$-terminal region. Interestingly, previous studies have shown that PDAC cells are characterized by increased expression of urokinase-type plasminogen activator (uPA) and uPA receptor, compared to normal pancreatic tissue, and by reduced expression of plasminogen activator inhibitor-1 (PAI-1) (20-22), indicating that indeed this proteolytic machinery is activated in PDAC. Of course, we cannot exclude that other proteases are also involved.
Given these premises, the question arises as to whether $\mathrm{CgA}$ cleavage is just an epiphenomenon of tumor growth or whether it can affect tumor physiology. The following observations suggest that $\mathrm{CgA}$ cleavage may contribute to regulate tumor growth. First, we have previously shown that $\mathrm{CgA}_{1-439}$ and $\mathrm{CgA}_{1-76}$ can regulate the adhesion of fibroblasts and endothelial cells, enhance the endothelial barrier function, and inhibit angiogenesis, whereas the fragment $\mathrm{CgA}_{1-373}$ can stimulate angiogenesis (5, $23,24)$. In particular, full-length $\mathrm{CgA}$ and the $\mathrm{N}$-terminal fragment $\mathrm{CgA}_{1-76}$ can inhibit endothelial cell migration, motility, sprouting, invasion and capillary-like structure formation induced by vascular endothelial growth factor, as well as angiogenesis induced by fibroblast growth factor- 2 ( 7 , 11). Vasostatin-1 can also inhibit, in endothelial cells, the nuclear translocation of hypoxia inducible factor- $1 \alpha$, a master regulator of angiogenesis $(7,11)$. On the other hand, other fragments, such as $\mathrm{CgA}_{1-373}$ and $\mathrm{CgA}_{352-372}$, can induce the release of fibroblast growth factor-2 from endothelial cells and promote angiogenesis $(5,14)$. Thus, CgA-related circulating polypeptides may form a balance of vasoactive factors, sometimes endowed of opposite effects, tightly regulated by $\mathrm{N}$ - and C-terminal proteolysis. 
A

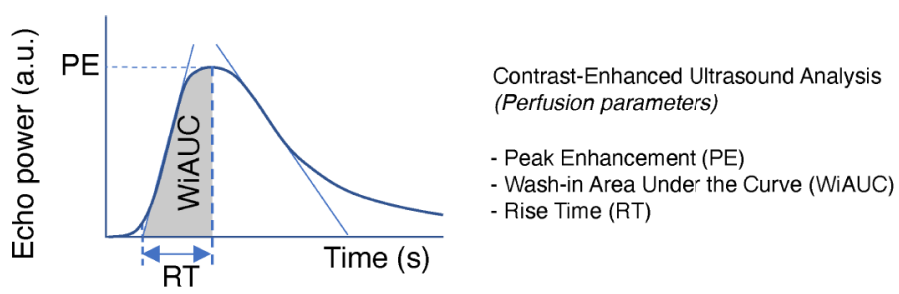

B
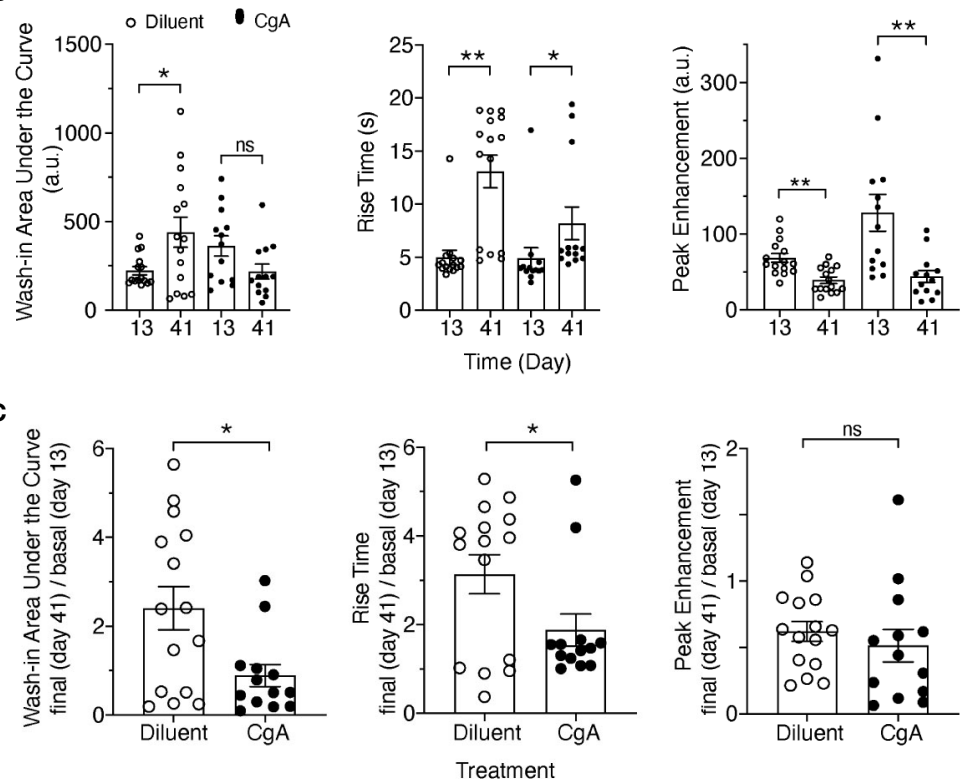

D

Wash-in Area Under the Curve map
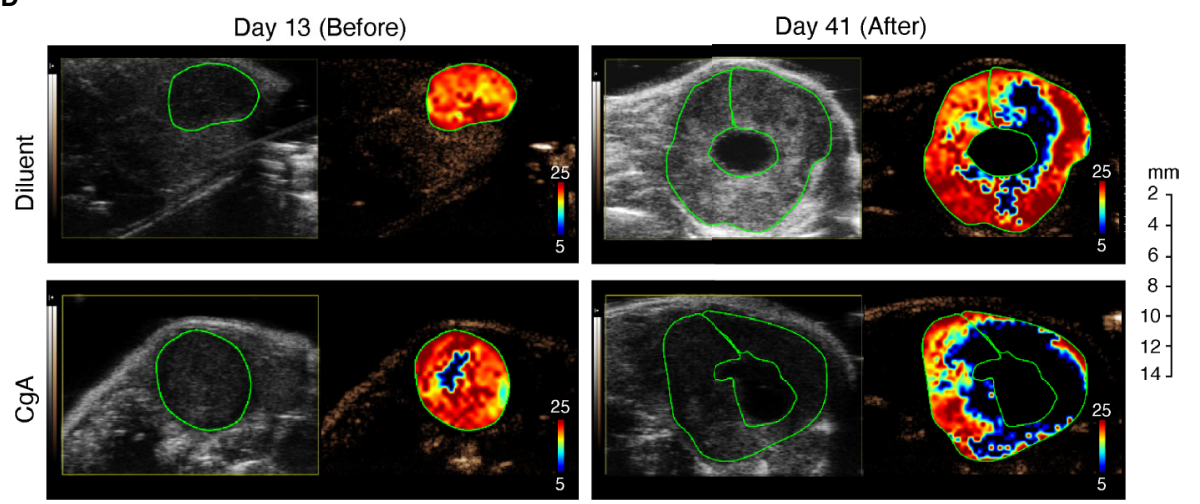

FIGURE 6 | Effect of CgA on the perfusion of orthotopic DT6606 pancreatic ductal adenocarcinoma (PDAC). DT6606 cells were implanted in the pancreas of syngeneic mice and treated with recombinant $\mathrm{CgA}_{1-439}(1.5 \mu \mathrm{g} / \mathrm{mouse}$, i.p. twice a week from day 14 to day 38 , eight times) in $0.9 \%$ sodium chloride (Diluent) or with Diluent alone ( $n=15$ mice/group). Tumor perfusion was monitored by contrast-enhanced ultrasound analysis one day before treatment (day 13 ) and three days after the last treatment (day 41). Perfusion parameters were calculated using a region of interest (ROI) corresponding to the entire tumor area [see (A) for a graph showing the parameters analyzed]. Perfusion parameters were: Peak Enhancement (PE, difference between the maximum amplitude in the curve and the baseline level, indicative of relative blood volume); Wash-in Area Under the Curve (WiAUC, area under the curve from starting enhancement to peak enhancement); rise time (RT, time frame during which intensity varies from 5\%-95\% of PE). (B) Tumor perfusion parameters at day 13 and 41 of mice treated with CgA or with Diluent. (C) Relative values of perfusion parameters at day 41 (final) over day 13 (basal). Outlier points were identified using the Prism software (ROUT, Q=5\%) and excluded. ${ }^{\star} P<0.05$; ${ }^{\star \star} P<0.01$ (two-tailed $t$-test); ns: not significant. (D) Gray scale tumor images and color-coded Wash-in Area Under the Curve (WiAUC) maps of representative tumors (with intra-tumoral cystic lesions) at day 13 and day 41, treated with Diluent or CgA as indicated. Green lines indicate the ROI analyzed. 
According to this view, our results show that limited digestion of CgA with plasmin can progressively convert its anti-angiogenic into pro-angiogenic activity in the endothelial cell-spheroid capillary-sprouting assay, whereas extensive digestion abrogated both effects (Figure 2C). It appears, therefore, that CgA degradation by plasmin represents a mechanism for the fine regulation of PDAC vascular biology and growth. This hypothesis is further supported by the results of in vivo studies showing that inhibition of $\mathrm{CgA}$ cleavage in Panc02-bearing mice, by systemic administration of aprotinin, is associated with a lower tumor-growth rate. Furthermore, systemic administration of antibodies against the binding site of $\mathrm{CgA}_{1-373}$ for neuropilin-1 (PGPQLR), an important receptor for its pro-angiogenic activity (8), significantly reduced Panc02-tumor growth (Figure 5). Notably, these antibodies cannot react with the cryptic PGPQLR site of full-length CgA (8), suggesting that this epitope, exposed in fragments, might represent a therapeutic target for specific antibodies. Finally, the results of contrastenhanced ultrasound analysis of tumors implanted in the pancreas of mice, showing that systemic administration of exogenous low-dose $\mathrm{CgA}_{1-439}$ can cause a significant reduction of tumor perfusion with microbubbles (Figure 6), lends further support to the hypothesis that this protein can indeed regulate the tumor vascular biology.

In conclusion, our findings suggest that PDAC can promote the cleavage of circulating CgA C-terminal region into vasoactive fragments, with important implications for PDAC pathophysiology and patient prognosis. Because of its potential pathophysiological function in the regulation of tumor biology and growth, CgA may represent a potential therapeutic target that warrants further exploration.

\section{DATA AVAILABILITY STATEMENT}

The raw data supporting the conclusions of this article will be made available by the authors, without undue reservation.

\section{ETHICS STATEMENT}

The studies involving human participants were reviewed and approved by San Raffaele Hospital Ethics Committee. The

\section{REFERENCES}

1. Kleeff J, Korc M, Apte M, La Vecchia C, Johnson CD, Biankin AV, et al. Pancreatic cancer. Nat Rev Dis Primers (2016) 2:16022. doi: 10.1038/nrdp. 2016.22

2. Siegel RL, Miller KD, Jemal A. Cancer statistics, 2018. CA Cancer J Clin (2018) 68(1):7-30. doi: 10.3322/caac. 21442

3. Rawla P, Sunkara T, Gaduputi V. Epidemiology of Pancreatic Cancer: Global Trends, Etiology and Risk Factors. World J Oncol (2019) 10(1):10-27. doi: $10.14740 /$ wjon 1166

4. Conroy T, Desseigne F, Ychou M, Bouche O, Guimbaud R, Becouarn Y, et al. Tumeurs Digestives of and P. Intergroup: FOLFIRINOX versus gemcitabine for metastatic pancreatic cancer. N Engl J Med (2011) 364(19):1817-25. doi: 10.1056/NEJMoa1011923 patients/participants provided their written informed consent to participate in this study. The animal study was reviewed and approved by San Raffaele Hospital Ethics Committee and by Ministero della Salute of Italy.

\section{AUTHOR CONTRIBUTIONS}

Conception/design: MR, AC. Data acquisition: VA, AG, ED, BC, $\mathrm{MM}, \mathrm{MB}, \mathrm{AD}, \mathrm{ACi}, \mathrm{EA}, \mathrm{MP}$, and FC. Data analysis/ interpretation: $\mathrm{MR}, \mathrm{VA}, \mathrm{AMG}, \mathrm{ED}, \mathrm{MM}, \mathrm{MB}, \mathrm{AD}, \mathrm{ACi}, \mathrm{EA}$, MPP, AE, MF, FC, LP, and AC. Drafting: MR, VA, and AC. Critical revision: $\mathrm{MR}, \mathrm{VA}, \mathrm{AG}, \mathrm{ED}, \mathrm{BC}, \mathrm{MM}, \mathrm{MB}, \mathrm{AD}, \mathrm{ACi}, \mathrm{EA}$, MP, AE, MF, FC, LP, and AC. All authors contributed to the article and approved the submitted version.

\section{FUNDING}

This work was supported by Associazione Italiana per la Ricerca sul Cancro (AIRC, grant IG-19220 and IG-23470, P.I. A Corti) and Fondazione AIRC under 5 per Mille 2019 - ID. 22737 program - P.I. MC Bonini, Group leader, A Corti.

\section{ACKNOWLEDGMENTS}

VA PhD studentship was supported by Ms Bianca Costanza Gioja Legacy Donation. We thank Laura Perani (Preclinical Imaging Facility) for the technical support provided for the invivo CEUS analysis of mice, and Annapaola Andolfo (Proteomic and Metabolomic Facility of San Raffaele Institute) for mass spectrometry analyses.

\section{SUPPLEMENTARY MATERIAL}

The Supplementary Material for this article can be found online at: https://www.frontiersin.org/articles/10.3389/fonc.2020.613582/ full\#supplementary-material

5. Crippa L, Bianco M, Colombo B, Gasparri AM, Ferrero E, Loh YP, et al. A new chromogranin A-dependent angiogenic switch activated by thrombin. Blood (2013) 121(2):392-402. doi: 10.1182/blood-2012-05-430314

6. Curnis F, Dallatomasina A, Bianco M, Gasparri A, Sacchi A, Colombo B, et al. Regulation of tumor growth by circulating full-length chromogranin A. Oncotarget (2016) 7(45):72716-32. doi: 10.18632/oncotarget.12237

7. Helle KB, Corti A. Chromogranin A: a paradoxical player in angiogenesis and vascular biology. Cell Mol Life Sci (2015) 78:339-48. doi: 10.1007/s00018-014-1750-9

8. Dallatomasina A, Gasparri AM, Colombo B, Sacchi A, Bianco M, Daniele T, et al. Spatiotemporal Regulation of Tumor Angiogenesis by Circulating Chromogranin A Cleavage and Neuropilin-1 Engagement. Cancer Res (2019) 79(8):1925-37. doi: 10.1158/0008-5472.CAN-18-0289

9. Taupenot L, Harper KL, O'Connor DT. The chromogranin-secretogranin family. N Engl J Med (2003) 348(12):1134-49. doi: 10.1056/NEJMra021405 
10. Banks P, Helle KB. The release of protein from the stimulated adrenal medulla. Biochem J (1965) 97:40C-1C. doi: 10.1042/bj0970040C

11. Corti A, Marcucci F, Bachetti T. Circulating chromogranin A and its fragments as diagnostic and prognostic disease markers. Pflugers Arch (2018) 470(1):199-210. doi: 10.1007/s00424-017-2030-y

12. Bianco M, Gasparri AM, Colombo B, Curnis F, Girlanda S, Ponzoni M, et al. Chromogranin A is preferentially cleaved into pro-angiogenic peptides in the bone marrow of multiple myeloma patients. Cancer Res (2016) 76:1781-91. doi: 10.1158/0008-5472.CAN-15-1637

13. Mahata SK, Corti A. Chromogranin A and its fragments in cardiovascular, immunometabolic, and cancer regulation. Ann N Y Acad Sci (2019) 1455 (1):34-58. doi: 10.1111/nyas.14249

14. Theurl M, Schgoer W, Albrecht K, Jeschke J, Egger M, Beer AG, et al. The neuropeptide catestatin acts as a novel angiogenic cytokine via a basic fibroblast growth factor-dependent mechanism. Circ Res (2010) 107 (11):1326-35. doi: 10.1161/CIRCRESAHA.110.219493

15. Rocca C, Grande F, Granieri MC, Colombo B, De Bartolo A, Giordano F, et al. The chromogranin A1-373 fragment reveals how a single change in the protein sequence exerts strong cardioregulatory effects by engaging neuropilin-1. Acta Physiol (Oxf) (2020) e13570. doi: 10.1111/apha.13570

16. Kim MP, Evans DB, Wang H, Abbruzzese JL, Fleming JB, Gallick GE. Generation of orthotopic and heterotopic human pancreatic cancer xenografts in immunodeficient mice. Nat Protoc (2009) 4(11):1670-80. doi: 10.1038/nprot.2009.171

17. Needles A, Arditi M, Rognin NG, Mehi J, Coulthard T, Bilan-Tracey C, et al. Nonlinear contrast imaging with an array-based micro-ultrasound system. Ultrasound Med Biol (2010) 36(12):2097-106. doi: 10.1016/j.ultrasmedbio. 2010.08.012

18. Mosli HH, Dennis A, Kocha W, Asher LJ, Van Uum SH. Effect of short-term proton pump inhibitor treatment and its discontinuation on chromogranin A in healthy subjects. J Clin Endocrinol Metab (2012) 97(9):E1731-5. doi: 10.1210/jc.2012-1548

19. Giusti M, Sidoti M, Augeri C, Rabitti C, Minuto F. Effect of short-term treatment with low dosages of the proton-pump inhibitor omeprazole on serum chromogranin A levels in man. Eur J Endocrinol (2004) 150(3):299303. doi: 10.1530/eje.0.1500299

20. Harvey SR, Hurd TC, Markus G, Martinick MII, Penetrante RM, Tan D, et al. Evaluation of urinary plasminogen activator, its receptor, matrix metalloproteinase-9, and von Willebrand factor in pancreatic cancer. Clin Cancer Res (2003) 9(13):4935-43.

21. Xue A, Scarlett CJ, Jackson CJ, Allen BJ, Smith RC. Prognostic significance of growth factors and the urokinase-type plasminogen activator system in pancreatic ductal adenocarcinoma. Pancreas (2008) 36(2):160-7. doi: 10.1097/ MPA.0b013e31815750f0

22. Warnecke-Eberz U, Prenzel KL, Baldus SE, Metzger R, Dienes HP, Bollschweiler E, et al. Significant down-regulation of the plasminogen activator inhibitor 1 mRNA in pancreatic cancer. Pancreas (2008) 36 (2):173-7. doi: 10.1097/MPA.0b013e31815ac538

23. Ferrero E, Scabini S, Magni E, Foglieni C, Belloni D, Colombo B, et al. Chromogranin A protects vessels against tumor necrosis factor alphainduced vascular leakage. FASEB J (2004) 18(3):554-6. doi: 10.1096/fj.030922fje

24. Gasparri A, Sidoli A, Sanchez LP, Longhi R, Siccardi AG, Marchisio PC, et al. Chromogranin A fragments modulate cell adhesion. Identification and characterization of a pro-adhesive domain. J Biol Chem (1997) 272 (33):20835-43. doi: 10.1074/jbc.272.33.20835

25. Corti A, Longhi R, Gasparri A, Chen F, Pelagi M, Siccardi AG. Antigenic regions of human chromogranin $\mathrm{A}$ and their topographic relationships with structural/functional domains. Eur J Biochem (1996) 235(1-2):275-80. doi: 10.111/j.1432-1033.1996.00275.x

26. Ratti S, Curnis F, Longhi R, Colombo B, Gasparri A, Magni F, et al. Structureactivity relationships of chromogranin A in cell adhesion. Identification of an adhesion site for fibroblasts and smooth muscle cells. J Biol Chem (2000) 275(38):29257-63. doi: 10.1074/jbc.M003796200

27. Celesti G, Di Caro G, Bianchi P, Grizzi F, Marchesi F, Basso G, et al. Early expression of the fractalkine receptor CX3CR1 in pancreatic carcinogenesis. Br J Cancer (2013) 109(9):2424-33. doi: 10.1038/bjc.2013.565

28. Corsello A, Di Filippo L, Massironi S, Sileo F, Dolcetta Capuzzo A, Gemma M, et al. Vasostatin-1: A novel circulating biomarker for ileal and pancreatic neuroendocrine neoplasms. PLoS One (2018) 13(5):e0196858. doi: 10.1371/ journal.pone.0196858

Conflict of Interest: The authors declare that the research was conducted in the absence of any commercial or financial relationships that could be construed as a potential conflict of interest.

Copyright (C) 2020 Reni, Andreasi, Gasparri, Dugnani, Colombo, Macchini, Bianco, Dallatomasina, Citro, Assi, Protti, Esposito, Falconi, Curnis, Piemonti and Corti. This is an open-access article distributed under the terms of the Creative Commons Attribution License (CC BY). The use, distribution or reproduction in other forums is permitted, provided the original author(s) and the copyright owner(s) are credited and that the original publication in this journal is cited, in accordance with accepted academic practice. No use, distribution or reproduction is permitted which does not comply with these terms. 